\title{
Perspectives on Molecular Materials-A Tribute to Professor Peter Day
}

\author{
Lee Martin $1, * \mathbb{C}$, Scott S. Turner ${ }^{2, *(\mathbb{D}}$, John D. Wallis ${ }^{1, *}$, Hiroki Akutsu ${ }^{3, * \mathbb{D}}$ and Carlos J. Gómez-García $4, *$ (D) \\ 1 Department of Chemistry and Forensics, School of Science and Technology, Nottingham Trent University, \\ Clifton Lane, Nottingham NG11 8NS, UK \\ 2 Chemistry Department, Faculty of Engineering and Physical Sciences, University of Surrey, \\ Guildford GU2 7XH, UK \\ 3 Department of Chemistry, Graduate School of Science, Osaka University, Osaka 560-0043, Japan \\ 4 Departamento de Química Inorgánica, Universidad de Valencia, C/Dr. Moliner 50, Burjasot, \\ 46100 Valencia, Spain \\ * Correspondence: lee.martin@ntu.ac.uk (L.M.); s.s.turner@surrey.ac.uk (S.S.T.); john.wallis@ntu.ac.uk (J.D.W.); \\ akutsu@chem.sci.osaka-u.ac.jp (H.A.); carlos.gomez@uv.es (C.J.G.-G.)
}

check for

updates

Citation: Martin, L.; Turner, S.S.; Wallis, J.D.; Akutsu, H.; GómezGarcía, C.J. Perspectives on Molecular Materials-A Tribute to Professor Peter Day. Magnetochemistry 2021, 7, 152. https://doi.org/10.3390/ magnetochemistry7120152

Received: 11 November 2021 Accepted: 19 November 2021 Published: 23 November 2021

Publisher's Note: MDPI stays neutral with regard to jurisdictional claims in published maps and institutional affiliations.

Copyright: (c) 2021 by the authors. Licensee MDPI, Basel, Switzerland. This article is an open access article distributed under the terms and conditions of the Creative Commons Attribution (CC BY) license (https:/ / creativecommons.org/licenses/by/ $4.0 /)$.

\section{Editorial}

Professor Peter Day FRS was born on 20 August 1938 in Kent (UK) and attended Maidstone Grammar School.

Peter completed his undergraduate studies at Wadham College, Oxford, followed by a DPhil in chemistry in 1965 under the supervision of Bob Williams. His thesis concerned Light Induced Charge Transfer in Solids. After his DPhil, Peter became a junior research fellow at St John's College, Oxford and later became an official fellow, tutor and university lecturer.

In 1988, Peter became the Director of the Institut Laue-Langevin in Grenoble (France). Peter was Director of the Royal Institution of Great Britain from 1991 to 1998, following illustrious predecessors, such as Humphry Davy (1801), Michael Faraday (1825), John Tyndall (1867) and James Dewar (1887). Peter continued the proud traditions of the Royal Institution with an extensive outreach program popularizing science to both adults and children, including the Royal Institution Christmas Lectures, which were televised each year in the UK and Japan.

At this time, Peter was also the Director of the Davy Faraday Research Laboratory at the RI where internationally leading research in solid-state chemistry produced many high-impact publications. As Fullerian Professor of Chemistry from 1991 to 2008, and subsequently Emeritus Professor at University College London, Peter continued to perform research in materials chemistry.

Peter received many honors and awards, including fellowship of the Royal Society in 1986 for his pioneering research on mixed valence compounds. The Royal Society of Chemistry introduced the Peter Day award in Materials Chemistry, which is awarded each year.

Maybe some of the readers will still remember an anecdote that reflects his very fast mind and his sense of humor. It took place in the last days of September 1995, during the gala dinner of the NATO Advanced Workshop: Magnetism, a Supramolecular Function, organized by his good friend Olivier Kahn, in Carcans (France). The dinner took place at the wine cellar Chateau Maucaillou in Medoc, near Bordeaux. At the end of the dinner, after several cups of good wine, Olivier Kahn stood up and proposed a toast suggesting that researchers should only sign our articles when the results are really good; otherwise, we should use a nickname. Peter stood up and asked: "Olivier, which is your true name?"

Peter passed away aged 81 on 19 May 2020.

Peter will be greatly missed by the guest editors of this Special Issue who were privileged to work closely with him. Peter's contributions to materials chemistry are well 
documented, but his friends and colleagues will remember the kindness of an inspirational mentor and a dear friend.

To pay tribute to his countless key contributions in many different domains in Materials Chemistry, the journal Magnetochemistry has decided to publish this memorial Special Issue (SI) entitled Perspectives on Molecular Materials-A Tribute to Professor Peter Day, including a total of twenty-one contributions from some of his collaborators and friends.

Among these contributions, there is a personal editorial written by $S$. Alvarez, from the University of Barcelona (Spain) [1], showing that Peter Day was not only an outstanding materials chemist, but he was also passionate about time and space. Prof. Álvarez shows the interest of Peter Day in the history of chemistry and of those institutions he belonged to, as well as in the many places he visited during his more than half a century-long scientific career.

Following chronological order, the first research contribution, by F. Setifi et al. at the University Ferhat Abbas of Sétif (Algeria), J. Reedijk at Leiden University (The Netherlands), C. I. Yang at Tunghai University (Taiwan), S. Bernés at Autónoma University of Puebla (Mexico), D. K. Geiger at SUNY college at Geneseo (USA) and G. Süheyla Kürkçüoğlu at Eskişehir Osmangazi University (Turkey), ref. [2], presents the first Mn(II) chain with alternating double end-to-end and end-on azido bridges showing coexistence of spincanted antiferromagnetic order (at $\mathrm{T}_{\mathrm{N}}=3.4 \mathrm{~K}$ ) and metamagnetism (with a critical field of ca. $30 \mathrm{mT}$ ). The analogous Co(II) compound shows weak ferromagnetic order below $16.2 \mathrm{~K}$.

The contribution by N. D. Kushch, E. B. Yagubskii et al. at the Institute of Problems of Chemical Physics (Russia), V. N. Zverev at the Institute of Solid-State Physics (Russia), E. Canadel at the Institute of Materials Science of Barcelona (Spain) and J. Yamada at the University of Hyogo (Japan), ref. [3], shows three new radical salts of a fused bis-TTF donor (BDH-TTP) with the octahedral paramagnetic $\left[\mathrm{ReF}_{6}\right]^{2-}$ anion and the tetrahedral diamagnetic one $\left[\mathrm{ReO}_{4}\right]^{-}$. The two salts with the $\left[\mathrm{ReF}_{6}\right]^{2-}$ anion are metallic down to low temperatures, whereas the salt with the $\left[\mathrm{ReO}_{4}\right]^{-}$anion is a semiconductor. No slow relaxation of magnetization was observed in the $\left[\mathrm{ReF}_{6}\right]^{2-}$ salts.

The contribution by D. Dragancea at the Institute of Chemistry in Chișinău (Moldova), M. Andruh et al. at the University of Bucharest (Romania) and G. Novitchi at the University Grenoble Alpes (France), ref. [4], reports three new cyano-bridged 3d-4f chain compounds containing alternating Gd-Fe, Dy-Fe and Dy-Co ions. The two Dy-containing compounds show slow relaxation of the magnetization, and the Dy-Co polymer is one the few known examples of chains of Single-Ion Magnets.

The contribution by T. Sugano at Meiji Gakuin University (Japan), H. Mori at the University of Tokyo (Japan) and S. J. Blundell and W. Hayes at the University of Oxford (UK), ref. [5], presents the magnetic properties of nitronyl nitroxide $(\mathrm{NN})$ and iminonitroxide (IN) functionalized organic radicals. Among other radicals, they show that the radical 2-benzo[b]thienyl-NN presents two magnetic dimers, one exhibiting ferro- and the other antiferromagnetic intermolecular interactions, in agreement with the crystal structure. They also show that the $4-\left(2^{\prime}\right.$-thienyl)phenyl-NN radical behaves as an alternating $1 \mathrm{D}$ antiferromagnet, also in agreement with its crystal structure.

The contribution by N. Marino and G. De Munno at the University of Calabria (Italy) and F. Lloret, M. Julve et al. at the University of Valencia (Spain), ref. [6], presents a very original novel $\mathrm{Cu}$ (II) oxalato-based 2D coordination polymer where the oxalato ligand shows two different coordination modes (bis-bidentate and bi/mono-dentate). This cyan 2D polymer shows an external control of the optical and magnetic properties, since it exhibits fast and selective adsorption of methylamine, which leads to a deep blue adsorbate that further transforms into a third polymer under vacuum. The magnetic properties of the three polymers show a unique switching from strong to weak antiferromagnetic interactions.

The contribution by B. Tsukerblat at Ben-Gurion University of the Negev (Israel) with A. Palii and S. Aldoshin at the Institute of Problems of Chemical Physics (Russia), ref. [7], shows a study of the dimeric molecular mixed-valence cell for quantum cellular automata 
(QCA) using the two-mode vibronic model. The authors consider a multielectron mixedvalence dimer of the type $\mathrm{d}^{2}-\mathrm{d}^{1}$, where the double exchange and the Heisenberg-Dirac-Van Vleck exchange interactions are operative together with the inter-center vibrational modes. The quantum-mechanical calculations show the possibility of combining the function of molecular QCA with that of spin switching in an electronic device and may guide the rational design of such multifunctional molecular electronic devices.

The contribution by S. J. Blundell at the University of Oxford, T. Lancaster at Durham University (UK), P. J. Baker and F. Pratt at Rutherford Appleton Laboratory at Oxfordshire (UK) and K. Sato et al. at Osaka City University (Japan), ref. [8], presents the unusual crystallization of an achiral organic radical in two chiral enantiomorphs that are mirror images of each other. The study of the magnetic properties of the crystals by muon-spin rotation experiments show the presence of long-range magnetic order below $1.10 \mathrm{~K}$ and of two oscillatory components showing different temperature dependences.

The contribution by S. S. Turner and J. Daniell at the University of Surrey (UK), H. Akutsu at Osaka University (Japan), P. N. Horton and S. J. Coles at the University of Southampton (UK) and V. Schünemann at the Technical University of Kaiserslautern (Germany), ref. [9], presents two novel salts with the anion $\left[\mathrm{Ni}(\mathrm{mnt})_{2}\right]^{-}(\mathrm{mnt}=$ maleonitriledithiolate) and two cationic Fe(II) complexes with derivatives of 2,6-bis(pyazolyl)pyridine or pyrazine. Both salts were characterized by variable temperature single crystal X-ray diffraction and magnetic measurements. The first salt displays an incomplete and gradual spin crossover up to $300 \mathrm{~K}$ and a rapid increase in the high-spin fraction between 300 and $350 \mathrm{~K}$. The second salt shows a gradual and more complete SCO response centered at $250 \mathrm{~K}$, confirmed by variable temperature Mössbauer spectroscopy. In both cases, the anionic moieties are isolated, and no electrical conductivity was observed.

The contribution by F. Pratt et al. at Rutherford Appleton Laboratory at Oxfordshire (UK), C. E. Anson and A. K. Powell at Karlsruhe Institute of Technology (Germany), J. Tang at Changchun Institute of Applied Chemistry (China) and S. J. Blundell at the University of Oxford (UK), ref. [10], reports a new molecular cluster system with $19 \mathrm{Fe}(\mathrm{III})$ ions arranged in a disc-like structure with a total spin $S=35 / 2$, that behaves as a single molecule magnet with an anisotropy barrier of $16 \mathrm{~K}$. Below $1.2 \mathrm{~K}$, the cluster presents an antiferromagnetic order due to the presence of weak inter-cluster interactions. The authors use neutron diffraction to determine the nature of the magnetic ordering and easy spin axis and inelastic neutron scattering to follow the magnetic order parameters and the magnetic excitations.

The contribution by S. Triki et al. at the University of Brest (France) and S. Benmanosur and C. J. Gómez-García at the University of Valencia (Spain), ref. [11], describes the synthesis and complete characterization of a rare anionic Fe(II) spin crossover (SCO) complex that shows a two-step SCO at around 170 and $298 \mathrm{~K}$, as confirmed by crystallographic and magnetic studies. After complete de-solvation of the complex at around $400 \mathrm{~K}$, the high temperature step shifts to lower temperatures and merges in only one gradual SCO at around $216 \mathrm{~K}$.

The contribution by B. Zhang et al. at the Chinese Academy of Sciences at Beijing (China) and Y. Zhang et al. at the University of Peking (China), ref. [12], presents a nice example of a crystal-to-crystal transformation of a monomeric anionic oxalato Co(II) complex into an oxalate-bridged zigzag chain via a dehydration process. The monomer shows weak antiferromagnetic interactions mediated by hydrogen bonds, whereas the chain presents an antiferromagnetic ordering at $8.2 \mathrm{~K}$.

The contribution by T. Prokhorova, E. Yagubskii et al. at the Institute of Problems of Chemical Physics (Russia), A. A. Bardin at the Russian Academy of Sciences at Chernogolovka (Russia) and V. N. Zverev at the Institute of Solid-State Physics (Russia), ref. [13], shows the crystal structures and physical properties of new organic (super)conductors of the $\beta$ "-(BEDTTTF $)_{4}\left(\mathrm{NH}_{4}\right)\left[\mathrm{Fe}^{3+}\left(\mathrm{C}_{2} \mathrm{O}_{4}\right)_{3}\right] \mathrm{G}$ family, where BEDT-TTF is bis(ethylenedithio)tetrathiafulvalene and $\mathrm{G}$ are different halo-pyridine derivatives. In all cases, the structures show the classical paramagnetic honeycomb anionic layers alternating with conducting layers of BEDT-TTF radical cations. One of the crystals (with 2-fluoropyridine) undergoes a monoclinic (C2/c) to 
triclinic $(P-1)$ phase transition at $100-150 \mathrm{~K}$, while the remaining salts keep the monoclinic phase in the temperature range $300-100 \mathrm{~K}$. All the salts are metallic conductors and one of them (with 2,6-difluoropyridine) shows the onset of a superconducting transition at $3.1 \mathrm{~K}$. The properties of these salts are compared with those of the known monoclinic phases of the family with different mono-halo-pyridines as solvent molecules.

The contribution by N. Avarvari et al. at the University of Angers (France), P. AubanSenzier at the University of Paris-Saclay (France), N. Vanthuyne at the CNRS at Marseille (France) and M. Almeida et al. at the University of Lisbon (Portugal), ref. [14], presents the synthesis and structural characterization of different series of radical cation salts with the organic precursors for chiral conductors: methyl-ethylenedithio-tetrathiafulvalene (1) and dimethyl-ethylenedithio-tetrathiafulvalene (2). Thus, the authors report the salts: $(1)_{2} \mathrm{AsF}_{6}$, $(1) \mathrm{I}_{3}$ and $(2) \mathrm{I}_{3}$ as racemic and as $(\mathrm{S})$ and $(\mathrm{R})$ enantiopure forms, the enantiomeric pure forms [(S)-1] $\mathrm{AsF}_{6} \cdot \mathrm{C}_{4} \mathrm{H}_{8} \mathrm{O}$ and [(R)-1] $\mathrm{AsF}_{6} \cdot \mathrm{C}_{4} \mathrm{H}_{8} \mathrm{O}$ and also the [(meso)-2] $\mathrm{PF}_{6}$ and [(meso)-2] $\mathrm{XO}_{4}$ $(\mathrm{X}=\mathrm{Cl}, \mathrm{Re})$ salts, containing the new donor (meso)-2. The crystallographic study shows the presence of a different packing in the latter case, compared to the chiral form, since the two methyl substituents adopt axial and equatorial conformations. The electrical properties show a quasi-metallic conductivity in $(\mathbf{1})_{2} \mathrm{AsF}_{6}$ in the high temperature regime, whereas the (meso)- 2 based salts are semiconductors.

The contribution by L. Martin et al. at Nottingham Trent University (UK), H. Akutsu et al. at Osaka University (Japan) and S. Imajo at the University of Tokyo (Japan), ref. [15], reports the synthesis, crystal structure and conducting properties of two new members of the Peter Day series, reported in 1995. These new salts are: the first superconductor with the diamagnetic tris(oxalato)aluminate anion (with a $\mathrm{T}_{\mathrm{C}}$ of $\approx 2.5 \mathrm{~K}$ ) and the first example of a $\beta^{\prime \prime}$ phase with the tris(oxalato)cobaltate anion.

The contribution by H. Akutsu et al. at Osaka University (Japan) and S. S. Turner at the University of Surrey (UK), ref. [16], reports three novel radical salts prepared with the organic donors bis(ethylenedithio)tetrathiafulvalene (BEDT-TTF) and bis(ethylenedithio) tetraselenafulvalene (BETS) with the organic anion 2-bromoethanesulfonate $\left(\mathrm{BrC}_{2} \mathrm{H}_{4} \mathrm{SO}_{3}{ }^{-}\right)$. The salt with BEDT-TTF presents a double $\beta$ " packing, whereas the two BETS salts present a double $\beta$ " packing or a $\theta$-type packing in the organic donors. The BEDT-TTF salt shows a metal-insulator transition at $\approx 70 \mathrm{~K}$, but the BETS salts are metallic down to $4.2 \mathrm{~K}$.

The contribution by C. Mathonière, P. Guionneau et al. at the University of Bordeaux (France), ref. [17], reports three new ionic salts containing $\left[\mathrm{M}(\mathrm{CN})_{8}\right]^{4-}\left(\mathrm{M}=\mathrm{Mo}^{\mathrm{IV}}\right.$ and $\left.\mathrm{W}^{\mathrm{IV}}\right)$ and large $\mathrm{Cu}(\mathrm{II})$ and $\mathrm{Zn}$ (II) complex cations containing a non-conventional motif built with the ligand tris(2-aminoethyl)amine. The three novel compounds show photomagnetic effects when irradiated with blue light at low temperatures, remarkable properties as long-lived photomagnetic metastable states for the $\left[\mathrm{Mo}(\mathrm{CN})_{8}\right]^{4-}$-based compounds above $200 \mathrm{~K}$ and rare efficient photomagnetic properties of the $\left[\mathrm{W}(\mathrm{CN})_{8}\right]^{4-}$-based compound. The contribution is completed with a comparison of the photomagnetic properties of the three reported compounds with the singlet-triplet conversion recently reported for the $\mathrm{K}_{4}\left[\mathrm{Mo}(\mathrm{CN})_{8}\right] \cdot 2 \mathrm{H}_{2} \mathrm{O}$ compound.

The contribution by T. Mallah, L. Catala et al. at the University of Paris-Saclay (France), ref. [18], shows the collective magnetic behavior of photo-switchable cyanide-bridged nanoparticles, based on the Prussian blue analogue CsCoFe, when embedded in different matrices with different concentrations. The authors study the effect of the intensity of light irradiation and show that the magnetization and AC magnetic susceptibility data suggest a collective magnetic behavior due to interparticle dipolar magnetic interactions, despite the nanoparticles having a size that places them in the superparamagnetic regime.

The contribution by J. D. Wallis et al. at Nottingham Trent University (UK) and $M$. Pilkington et al. at Brock University (Canada), ref. [19], reports the syntheses of new BEDTTTF derivatives with (i) one ethynyl group (HC $\equiv \mathrm{C}-$ ), (ii) two (n-heptyl), (iii) four (n-butyl) alkyl side chains, (iv) two trans acetal $\left(-\mathrm{CH}(\mathrm{OMe})_{2}\right)$ groups, (v) two trans aminomethyl $\left(-\mathrm{CH}_{2} \mathrm{NH}_{2}\right)$ groups, or (vi) an iminodiacetate $\left(-\mathrm{CH}_{2} \mathrm{~N}\left(\mathrm{CH}_{2} \mathrm{CO}_{2}{ }^{-}\right)_{2}\right.$ side chain. The contribution also reports the synthesis and magnetic properties of three transition metal salts 
from the latter donor, as well as the synthesis of three tris-donor systems bearing three BEDT-TTF derivatives with ester links to a core derived from benzene-1,3,5-tricarboxylic acid. Authors discuss the stereochemistry and molecular structure of the donors and describe the X-ray crystal structures of two BEDT-TTF donors: one with two $\mathrm{CH}(\mathrm{OMe})_{2}$ groups and one with a $-\mathrm{CH}_{2} \mathrm{~N}\left(\mathrm{CH}_{2} \mathrm{CO}_{2} \mathrm{Me}\right)_{2}$ side chain.

The perspective article by M. L. Mercuri et al. at the University of Cagliari (Italy) and S. A. Sahadevan at the Royal Institute of Technology at Stockholm (Sweden), ref. [20], presents a review of coordination networks incorporating redox activity to enhance the magnetic, conducting and optical properties of these lattices. The contribution reviews the compounds prepared with quinone derivatives as redox-active linkers, since they have been widely used for electrode materials, flow batteries, pseudo-capacitors and other applications, thanks to the reversible two-electron redox reaction to form hydroquinone dianions via intermediate semiquinone radicals. Furthermore, these quinone linkers can be easily functionalized with different substituents and functional groups, making them excellent building blocks to prepare multifunctional tunable metal-organic frameworks (MOFs). The authors present an overview of the recent advances on benzoquinone-based MOFs, including key examples where magnetic and/or conducting properties are tuned/switched by playing with the redox activity.

Finally, there is a comprehensive review by S. Benmansour and C. J. Gómez-García at the University of Valencia (Spain), ref. [21], with all the reported series of (super)conducting and magnetic radical salts prepared with organic donors of the tetrathiafulvalene (TTF) family and oxalato-based metal complexes. The review starts with the Peter Day series of magnetic superconductors with the monoclininc $\beta$ " packing prepared with the donor bis(ethylenedithio)tetrathiafulvalene (BEDT-TTF) and continues with the orthorhombic pseudo-k semiconducting polymorphs, also reported with BEDT-TTF for the first time by P. Day et al. The exhaustive review shows other series prepared with different oxalate-based complexes, including monomers, such as $\left[\mathrm{M}^{\mathrm{III}}\left(\mathrm{C}_{2} \mathrm{O}_{4}\right)_{3}\right]^{3-}$, $\left[\mathrm{Ge}\left(\mathrm{C}_{2} \mathrm{O}_{4}\right)_{3}\right]^{2-}$ or $\left[\mathrm{Cu}\left(\mathrm{C}_{2} \mathrm{O}_{4}\right)_{2}\right]^{2-}$, dimers, such as $\left[\mathrm{Fe}_{2}\left(\mathrm{C}_{2} \mathrm{O}_{4}\right)_{5}\right]^{4-}$, trimers, such as $\left[\mathrm{M}^{\mathrm{II}}\left(\mathrm{H}_{2} \mathrm{O}\right)_{2}\left[\mathrm{M}^{\mathrm{III}}\left(\mathrm{C}_{2} \mathrm{O}_{4}\right)_{3}\right]_{2}\right]^{4-}$ and homoor heterometallic extended 2D layers, such as $\left[\mathrm{M}^{\mathrm{II}} \mathrm{M}^{\mathrm{III}}\left(\mathrm{C}_{2} \mathrm{O}_{4}\right)_{3}\right]^{-}$and $\left[\mathrm{M}^{\mathrm{II}}{ }_{2}\left(\mathrm{C}_{2} \mathrm{O}_{4}\right)_{3}\right]^{2-}$. In addition to the different structural types, the review describes the magnetic properties (dia-, para-, antiferro-, ferromagnetism or long-range magnetic ordering), coexisting with electrical properties (semiconductivity, metallic conductivity or superconductivity) in these salts. The review finishes including the radical salts prepared with oxalate-based complexes and lattices with other organic donors of the TTF-type donors.

As can be seen in the previous list of contributions, Peter Day not only left a long list of key contributions in many different domains in materials chemistry, but also an endless list of collaborators and friends in many different countries. We would like to thank all of them for their high-level contributions in this Special Issue devoted to his memory. We are sure that Peter would have enjoyed reading all of them as much as we will miss him.

Funding: This research received no external funding.

Conflicts of Interest: The authors declare no conflict of interest.

\section{References}

1. Alvarez, S. Peter Day's Exploration of Time and Space. Magnetochemistry 2021, 7, 103. [CrossRef]

2. Benamara, N.; Setifi, Z.; Yang, C.; Bernès, S.; Geiger, D.K.; Kürkçüoğlu, G.S.; Setifi, F.; Reedijk, J. Coexistence of Spin Canting and Metamagnetism in a One-Dimensional Mn(II) Compound Bridged by Alternating Double End-to-End and Double End-on Azido Ligands and the Analog Co(II) Compound. Magnetochemistry 2021, 7, 50. [CrossRef]

3. Kushch, N.D.; Shilov, G.V.; Buravov, L.I.; Yagubskii, E.B.; Zverev, V.N.; Canadell, E.; Yamada, J. New Radical Cation Salts Based on BDH-TTP Donor: Two Stable Molecular Metals with a Magnetic $\left[\operatorname{ReF}_{6}\right]^{2-}$ Anion and a Semiconductor with a $\left[\mathrm{ReO}_{4}\right]^{-}$Anion. Magnetochemistry 2021, 7, 54. [CrossRef]

4. Dragancea, D.; Novitchi, G.; Mădălan, A.M.; Andruh, M. New Cyanido-Bridged Heterometallic 3d-4f 1D Coordination Polymers: Synthesis, Crystal Structures and Magnetic Properties. Magnetochemistry 2021, 7, 57. [CrossRef]

5. Sugano, T.; Blundell, S.J.; Hayes, W.; Mori, H. Magnetic and Structural Properties of Organic Radicals Based on Thienyl- and Furyl-Substituted Nitronyl Nitroxide. Magnetochemistry 2021, 7, 62. [CrossRef] 
6. Marino, N.; Calatayud, M.L.; Orts-Arroyo, M.; Pascual-Álvarez, A.; Moliner, N.; Julve, M.; Lloret, F.; De Munno, G.; Ruiz-García, R.; Castro, I. Magnetic Switching in Vapochromic Oxalato-Bridged 2D Copper(II)-Pyrazole Compounds for Biogenic Amine Sensing. Magnetochemistry 2021, 7, 65. [CrossRef]

7. Tsukerblat, B.; Palii, A.; Aldoshin, S. In Quest of Molecular Materials for Quantum Cellular Automata: Exploration of the Double Exchange in the Two-Mode Vibronic Model of a Dimeric Mixed Valence Cell. Magnetochemistry 2021, 7, 66. [CrossRef]

8. Blundell, S.J.; Lancaster, T.; Baker, P.J.; Pratt, F.L.; Shiomi, D.; Sato, K.; Takui, T. The Internal Field in a Ferromagnetic Crystal with Chiral Molecular Packing of Achiral Organic Radicals. Magnetochemistry 2021, 7, 71. [CrossRef]

9. Turner, S.S.; Daniell, J.; Akutsu, H.; Horton, P.N.; Coles, S.J.; Schünemann, V. New Spin-Crossover Compounds Containing the [Ni(mnt)] Anion (mnt = Maleonitriledithiolate). Magnetochemistry 2021, 7, 72. [CrossRef]

10. Pratt, F.L.; Guidi, T.; Manuel, P.; Anson, C.E.; Tang, J.; Blundell, S.J.; Powell, A.K. Neutron Studies of a High Spin Fe 19 Molecular Nanodisc. Magnetochemistry 2021, 7, 74. [CrossRef]

11. Cuza, E.; Benmansour, S.; Cosquer, N.; Conan, F.; Gómez-García, C.J.; Triki, S. Solvent-Induced Hysteresis Loop in Anionic Spin Crossover (SCO) Isomorph Complexes. Magnetochemistry 2021, 7, 75. [CrossRef]

12. Zhang, B.; Zhang, Y.; Chang, G.; Wang, Z.; Zhu, D. Crystal-to-Crystal Transformation from $\mathrm{K}_{2}\left[\mathrm{Co}\left(\mathrm{C}_{2} \mathrm{O}_{4}\right)_{2}\left(\mathrm{H}_{2} \mathrm{O}\right)_{2}\right] \cdot 4 \mathrm{H}_{2} \mathrm{O}$ to $\mathrm{K}_{2}\left[\mathrm{Co}\left(\mu-\mathrm{C}_{2} \mathrm{O}_{4}\right)\left(\mathrm{C}_{2} \mathrm{O}_{4}\right)\right]$. Magnetochemistry 2021, 7, 77. [CrossRef]

13. Prokhorova, T.G.; Yagubskii, E.B.; Bardin, A.A.; Zverev, V.N.; Shilov, G.V.; Buravov, L.I. Influence of the Size and Shape of Halopyridines Guest Molecules G on the Crystal Structure and Conducting Properties of Molecular (Super)Conductors of (BEDT-TTF $)_{4} \mathrm{~A}^{+}\left[\mathrm{M}^{3+}\left(\mathrm{C}_{2} \mathrm{O}_{4}\right)_{3}\right]$.G Family. Magnetochemistry 2021, 7, 83. [CrossRef]

14. Mroweh, N.; Bogdan, A.; Pop, F.; Auban-Senzier, P.; Vanthuyne, N.; Lopes, E.B.; Almeida, M.; Avarvari, N. Chiral Radical Cation Salts of Me-EDT-TTF and DM-EDT-TTF with Octahedral, Linear and Tetrahedral Monoanions. Magnetochemistry $2021,7,87$. [CrossRef]

15. Blundell, T.J.; Brannan, M.; Mburu-Newman, J.; Akutsu, H.; Nakazawa, Y.; Imajo, S.; Martin, L. First Molecular Superconductor with the Tris(Oxalato)Aluminate Anion, $\beta^{\prime \prime}$-(BEDT-TTF $)_{4}\left(\mathrm{H}_{3} \mathrm{O}\right) \mathrm{Al}\left(\mathrm{C}_{2} \mathrm{O}_{4}\right)_{3} \cdot \mathrm{C}_{6} \mathrm{H}_{5} \mathrm{Br}$, and Isostructural Tris(Oxalato)Cobaltate and Tris(Oxalato)Ruthenate Radical Cation Salts. Magnetochemistry 2021, 7, 90. [CrossRef]

16. Akutsu, H.; Koyama, Y.; Turner, S.S.; Nakazawa, Y. Structures and Properties of New Organic Molecule-Based Metals, (D) ${ }_{2} \mathrm{BrC}_{2} \mathrm{H}_{4} \mathrm{SO}_{3}$ [D = BEDT-TTF and BETS]. Magnetochemistry 2021, 7, 91. [CrossRef]

17. Qi, X.; Guionneau, P.; Lafon, E.; Perot, S.; Kauffmann, B.; Mathonière, C. New Photomagnetic Ionic Salts Based on $\left[\mathrm{Mo}^{\mathrm{IV}}(\mathrm{CN})_{8}\right]^{4-}$ and $\left[\mathrm{W}^{\mathrm{IV}}(\mathrm{CN})_{8}\right]^{4-}$ Anions. Magnetochemistry 2021, 7, 97. [CrossRef]

18. Trinh, L.; Rivière, E.; Mazerat, S.; Catala, L.; Mallah, T. Collective Magnetic Behavior of $11 \mathrm{~nm}$ Photo-Switchable CsCoFe Prussian Blue Analogue Nanocrystals: Effect of Dilution and Light Intensity. Magnetochemistry 2021, 7, 99. [CrossRef]

19. Yang, S.; Zecchini, M.; Brooks, A.C.; Krivickas, S.J.; Dalligos, D.M.; Matuszek, A.M.; Stares, E.L.; Pilkington, M.; Wallis, J.D. Synthesis of New Derivatives of BEDT-TTF: Installation of Alkyl, Ethynyl, and Metal-Binding Side Chains and Formation of Tris(BEDT-TTF) Systems. Magnetochemistry 2021, 7, 110. [CrossRef]

20. Monni, N.; Oggianu, M.; Ashoka Sahadevan, S.; Mercuri, M.L. Redox Activity as a Powerful Strategy to Tune Magnetic and/or Conducting Properties in Benzoquinone-Based Metal-Organic Frameworks. Magnetochemistry 2021, 7, 109. [CrossRef]

21. Benmansour, S.; Gómez-García, C.J. The Peter Day Series of Magnetic (Super)Conductors. Magnetochemistry 2021, 7, 93. [CrossRef] 